\title{
$\begin{array}{ll}\text { Research Square } & \text { Preprints are preliminary reports that have not undergone peer review. } \\ \text { They should not be considered conclusive, used to inform clinical practice, }\end{array}$
}

\section{Preparation and Characterization of Ecofriendly food Packaging Material by Smooth Hound Skin Gelatin Films/TiO2}

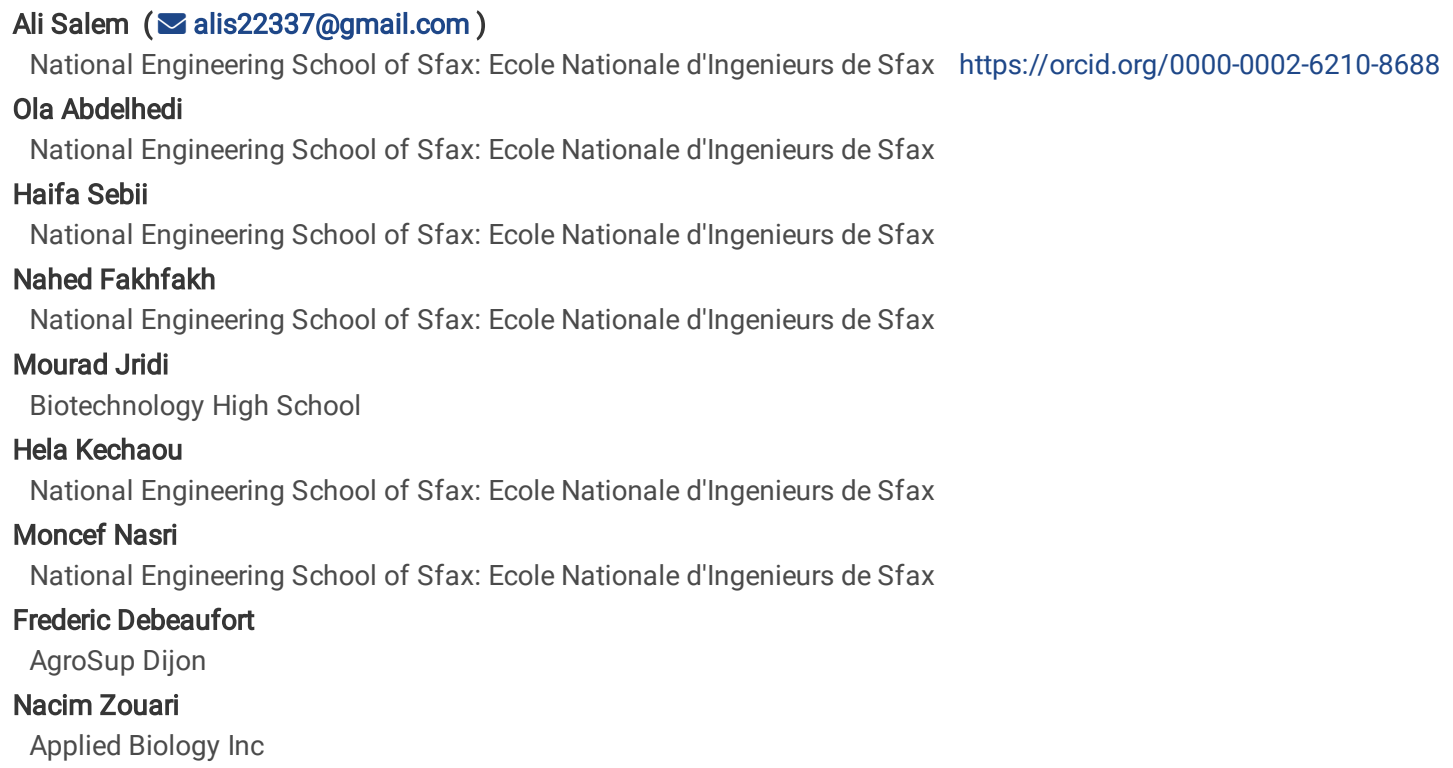

Keywords: Gelatin films, Mustelus mustelus, Incorporation, Physicochemical property, Titanium dioxide, Food packaging.

Posted Date: February 15th, 2022

DOI: https://doi.org/10.21203/rs.3.rs-1239574/v1

License: @ (1) This work is licensed under a Creative Commons Attribution 4.0 International License. Read Full License 


\section{Abstract}

The effect of $\mathrm{TiO}_{2}$ on structural properties of gelatin films, obtained by solution casting method, was investigated. The results showed that $\mathrm{TiO}_{2}$ incorporation

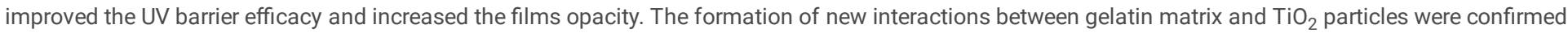
by FTIR analysis. A decrease in elongation at break was observed for gelatin-based film when $\mathrm{TiO}_{2}$ content increased, whereas the tensile strength increased. The microstructure analysis revealed heterogeneous structure due to the presence of a small aggregate with increasing the $\mathrm{TiO}_{2}$ ratio. $\mathrm{The}$ addition of $\mathrm{TiO}_{2}$ increased the contact angles, which could be related to the hydrophobic nature of the $\mathrm{TiO}_{2}$ incorporated films proved by the low swelling capacity of these films. In addition, incorporation of $\mathrm{TiO}_{2}$ particles into gelatin matrix improved barrier properties of gelatin films making it able to be used in water-soluble food or pharmaceutical packaging as a UV protective.

\section{Introduction}

Biopolymers are considered as a promising alternative to petrochemical-based polymers for the sake of environment protection and sustainable development [1]. Several market studies showed that with feedstock's low cost and technologies, biopolymer demand growth exceeds an annual growth rate of 4.5 times the actual production for the duration between 2014 and 2019 [2]. Moreover, consumers are also more and more interested in products based on biopolymers regarding their low toxicity, biodegradability and biocompatibility [2].

Actually, the fish processing industries as well as the fish markets are providing large amounts of by-products and wastes ( 30 to $50 \%$ of fish corpse) serving as raw materials for extraction of various biopolymers. Among these wastes, bones [3], exoskeletons [4], viscera [5] and skin [6] are the most exploited. Skin gelatin from multiple fish species, such as Nile tilapia (Oreochromisniloticus) [7] and Jullien's golden carp (Probarbusjullieni) [8] were extracted and characterized. Gelatin is a protein produced by thermal denaturation of collagen. It is widely used in food industries as thickening agent in desserts, stabilizer in ice cream preparations, texturizer in confections' production, and as food foam and gelling agent [9]. In addition, the intrinsic properties of gelatin, especially its excellent film forming ability, offer nowadays substantial advantages for use in membrane technology. In fact, gelatin-based membranes showed growing interest for water treatment [10], gas separation, micro and ultra-separation as well as for tissue engineering [11] where it's used not only as barriers to volatile compounds, oxygen and carbon dioxide, but also as carriers of wide variety of substances, such as antioxidants, antibacterial compounds, colorants and nutrients.

Nevertheless, properties of gelatin membranes (mechanical and barrier properties) depends strongly on the physical and chemical characteristics of the gelatin, which were in relation with the amino acids composition depending especially on fish species, thereby restricting their use as packaging material. Using particles in biopolymer-based llms is a promising alternative to improve both mechanical and thermal properties [12]. Among these particles, titanium dioxide $\left(\mathrm{TiO}_{2}\right)$ is the most commonly manufactured. In fact, $\mathrm{TiO}_{2}$ particles are gaining special attention owing to their low cost, high stability, photo-catalytic and anticorrosive properties. A recent study has shown that $\mathrm{TiO}_{2}$ particles could avoid light induced oxidation and decomposition when used in food packaging systems [13]. In addition, theses have been used as an UV protective skin compound, since they have wide UV spectrum-attenuation characteristics. A supplementary layer, of titanium dioxide as an example, is often added to prevent silver oxidation and to reduce its concentration in antimicrobial activities

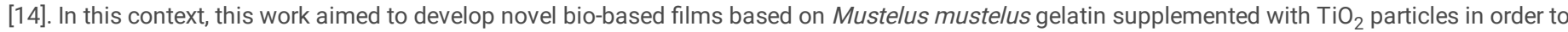
substitute plastic by biodegradables films, which could be used as food or pharmaceutical packaging. The physicochemical, thermal, mechanical and antioxidant properties of the prepared films were investigated.

\section{Materials And Methods}

\subsection{Materials}

Fish skin gelatin extracted from smooth hound fish (M. mustelus) was used as biopolymer for films preparation. Anhydrous glycerol was purchased from Fluka (98\% purity, Fluka Chemical, Germany) and was used as plasticizer. Titanium dioxide $\left(\mathrm{TiO}_{2 ;} ; 6.8 \mathrm{~g} \mathrm{~mol}{ }^{-1}\right)$ was used as an additive in gelatin-based films.

\subsection{Film preparation}

Film forming solutions (FFS) were prepared by dissolving fish gelatin $3 \%(\mathrm{w} / \mathrm{v})$ in distilled water at $60^{\circ} \mathrm{C}$ for 30 min. Then, Titanium dioxide $\left(\mathrm{TiO}_{2}\right) \mathrm{was}$ added at different levels of $0.01,0.02$ and $0.03 \%$. To enhance the dispersion of the $\mathrm{TiO}_{2}$, the $\mathrm{FFS}$ were treated by an ultrasonic treatment for 1 hour. Glycerol was added as a plasticizer to the solutions at a concentration of $15 \%\left(\mathrm{w} / \mathrm{w}\right.$ dry gelatin matter) and the FFS were maintained under stirring for 30 min at $40^{\circ} \mathrm{C}$. Subsequently, a volume of $25 \mathrm{~mL}$ of each film forming solution was cast in polystyrene $12 \times 12 \mathrm{~cm}$ square Petri dishes. All FFS were dried in a ventilated climatic chamber (KBF 240 Binder, ODIL, France) at $25^{\circ} \mathrm{C}$ and $50 \%$ relative humidity (RH) for $48 \mathrm{~h}$. Control film were made from pure gelatin and three types of films were obtained based on $\mathrm{TiO}_{2}$ level:

- $\mathrm{F}-\mathrm{GTiO}_{2}$ 0.01\%: Gelatin-based Film containing $0.01 \% \mathrm{TiO}_{2}$.

- F-GTiO $20.02 \%$ : Gelatin-based Film containing $0.02 \% \mathrm{TiO}_{2}$.

- F-GTiO $20.03 \%$ : Gelatin-based Film containing $0.03 \% \mathrm{TiO}_{2}$.

\subsection{Film thickness}


Digital thickness gauge (PosiTector 6000, DeFelsko Corporation, USA) was used to measure the films thickness. Four measurements at different positions were taken from each film sample. The mean value was used in calculation and taken into account for mechanical properties.

\subsection{Swelling and solubility of films}

Film solubility was determined based on the method reported by Gennadios et al. [15]. The conditioned film samples $(1 \times 1 \mathrm{~cm})$ were weighed and transferred to $50 \mathrm{~mL}$ centrifuge tube containing $10 \mathrm{~mL}$ of distilled water and stirred at room temperature for $24 \mathrm{~h}$ at a speed of $250 \mathrm{rpm}$ and at temperature of $25^{\circ} \mathrm{C}$.

After centrifugation at $6000 \mathrm{rpm}$ for $10 \mathrm{~min}$, samples were dried at $105^{\circ} \mathrm{C}$ for $24 \mathrm{~h}$ to determine the remaining pieces of films. Water solubility (WS) was calculated according to the following equation:

$W S=\left[\left(W_{i}-W_{f}\right) / W_{i}\right] \times 100$

Where $\mathrm{W}_{\mathrm{i}}$ : initial film weight $(\mathrm{g})$; $\mathrm{W}_{\mathrm{f}}$ : final dry weight of film non solubilized in water $(\mathrm{g})$. All tests were carried out in triplicate.

Water sorption or swelling ratio (SR) of film samples was determined according the method of Lavorgnaet al. [16], with slide modifications. After desiccation, the film sample was cuted into $1 \times 1 \mathrm{~cm}^{2}$, and then weighed to determine their dry mass. The weighed samples were immersed in closed pots containing 30 $\mathrm{mL}$ of distilled water $(\mathrm{pH}=7)$ and stored at $25^{\circ} \mathrm{C}$. The swelling ratio of the samples was evaluated by measuring their weight increment periodically until equilibrium. Before weighing, the surfaces of films were gently blotted with a filter paper to remove the water excess. Weight measurements were executed using a balance accurate to $0.001 \mathrm{~g}$. To confirm its repeatability, the procedure of each samples were realized in triplicate. The water gain of each sample was calculated as follows:

$\mathrm{SR}=\left[\left(\mathrm{W}_{\mathrm{s}}-\mathrm{W}_{\mathrm{d}}\right) / \mathrm{W}_{\mathrm{d}}\right] \times 100$

Where Ws: wet film weight (g); $\mathrm{W}_{\mathrm{d}}$ : dry weight of film (g).

\subsection{Spectroscopic analysis}

Ultraviolet-visible (UV-Vis) spectroscopy was performed by using a UV-Visible spectrophotometer (SAFAS UVmc, Monaco, France) in the wavelength range from 200 to $800 \mathrm{~nm}$. All measurements were performed at $25^{\circ} \mathrm{C}$ and $50 \% \mathrm{RH}$ andfilms were directly placed in the spectrophotometer test cell after cutting into $1 \times 3 \mathrm{~cm}$ rectangle. Air was used as a reference. Transmittance and opacity of films were calculated as follows:

Transmittance $(\%)=-\log ($ film transmission) $/$ film thickness

Opacity $(\%)=-\log ($ transmission at $600 \mathrm{~nm}) /$ film thickness

Furthermore, FTIR-ATR spectra of film samples were determined using a Perkin-Elmer spectrometer (PerkinElmer (Model Spectrum 65), Brentwood, USA) equipped with an attenuated total reflectance (ATR) accessory with a ZnSe crystal, 32 scans were collected with $4 \mathrm{~cm}^{-1} \mathrm{resolutions} \mathrm{in} \mathrm{the} 600-4000 \mathrm{~cm}^{-1}$ wavelength range. Calibration was done using background spectrum recorded from the clean and empty cell at $25^{\circ} \mathrm{C}$. For FTIR-ATR data treatment, the Spectrum Suite ES software was used.

\subsection{Mechanical property}

Tensile strength (TS, MPa) and elongation at break (EAB, \%) of film samples were determined using a texture analyzer (Stable Micro Systems, TA-HD plus model, Godalming, UK) according to the standard method ISO 527-3 (equivalent to ASTM D882 method). Rectangular film samples (2.5 8 cm) were sized using a standardized precision cutter (Thwing-Albert JD, West Berlin, USA) in order to get tensile test piece with an accurate width and parallel sides throughout the entire length. Film samples were then placed in the extension grips of the testing machine and stretched uniaxially with a cross-head speed of $50 \mathrm{~mm} / \mathrm{min}$ until breaking. The maximum load and the final extension at break were determined from the corresponding stress-strain curves and used for calculation of TS and EAB. Measurements were carried out at room temperature $\left(25 \pm 2^{\circ} \mathrm{C}\right)$ and relative humidity $(40 \pm 5 \%)$ and five samples for each formulation were tested.

\subsection{Scanning electron microscopy (SEM) photographs}

The surface morphology and cross sections of the films were observed by scanning electron microscopy (SEM) (TESCAN MIRA 3 XMU, Brno, Czech Republic). Before scanning, the films were coated with a thin layer of gold and then inspected with an accelerating voltage of $20 \mathrm{kV}$.

\subsection{Thermal property}

Thermal properties of films were studied using a Differential Scanning Calorimeter (DSC Q20 METTLER TOLEDO, Langacher, Switzerland). Around 5 mg of each film was subjected to a double heating-cooling cycle. Nitrogen was used as the purge gas at a flow rate of $25 \mathrm{~mL} / \mathrm{min}$. Glass transition temperatures (Tg) were determined from the resulting reverse heat flow thermograms as midpoints between the onset and end temperatures of step changes in heat flow observed during heating and identified as second-order transitions. Samples were firstly cooled at a rate of $10^{\circ} \mathrm{C} / \mathrm{min}$ until reaching $-80^{\circ} \mathrm{C}$ and heated at a rate of $20^{\circ} \mathrm{C} / \mathrm{min}$ up to $150^{\circ} \mathrm{C}$.All the samples were conditioned at $25^{\circ} \mathrm{C}$ and $0 \% \mathrm{RH}$ for two weeks before the measurements. Only the second heating run was considered for the determination of the glass transition temperature in aim to prevent bias due to mechanical stress release (relaxation peaks) on the $\mathrm{Tg}$ determination.

\subsection{Water contact angle}


The contact angle measurements were carried out using the sessile drop method on a goniometer (KrussDrop Shape Analyzer 30S, Hamburg, Germany), equipped with an image analysis software (ADVANCE). A droplet of each liquid $(\sim 2 \mu \mathrm{L})$ was deposited on the film surface with a precision syringe. Then, the method is based on image processing and curve fitting for contact angle measurement from a theoretical meridian drop profile, determining contact angle between the baseline of the drop and the tangent at the drop boundary. Contact angle was measured on both sides of the drop and averaged. Four measurements per films were carried out. All the tests were conducted in an environmental chamber with a constant environment at a temperature of $25 \pm 2^{\circ} \mathrm{C}$ and a relative humidity of $50 \pm 1 \%$.

\subsection{Color parameters}

Color development was studied using a CIE colorimeter (Konica Minolta, Osaka, Japan). Films color was expressed as L* (lightness/brightness), a* (redness/greenness) and $b^{*}$ (yellowness/blueness) values. The difference and the saturation (Chroma) in color ( $\Delta \mathrm{E}$ and $\mathrm{C}^{*}$ respectively) of gelatin based films incorporated with $\mathrm{TiO}_{2}$ was determined referred to the control films (films without $\mathrm{TiO}_{2}$ ) as follows:

$\Delta \mathrm{E}=\sqrt{\left(\mathrm{L}^{*}-\mathrm{L}_{\mathrm{C}}^{*}\right)^{2}+\left(\mathrm{a}^{*}-\mathrm{a}_{\mathrm{c}}^{*}\right)^{2}+\left(\mathrm{b}^{*}-\mathrm{b}_{\mathrm{c}}^{*}\right)^{2}}$

$c^{*}=\sqrt{\left(a^{*}-a_{c}^{*}\right)^{2}+\left(b^{*}-b_{c}^{*}\right)^{2}}$

$\mathrm{L}^{*}, \mathrm{a}^{*}$ and $\mathrm{b}^{*}$ are the color parameters of films incorporated with $\mathrm{TiO}_{2} ; \mathrm{L}^{*}{ }^{\prime} \mathrm{a}^{*}{ }_{\mathrm{c}}$ and $\mathrm{b}_{\mathrm{c}}{ }_{\mathrm{c}}$ are the color parameters of their control films.

\subsection{Statistical analysis}

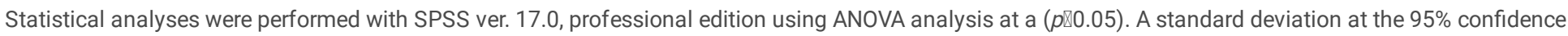
level was used to compare all parameters analyzed for the different films ratios.

\section{Results And Discussion}

\subsection{Color and spectral properties}

Film color is of utmost importance, since it has a direct impact on the appearance of a packaged product and may influence its acceptability by the consumer (2002). The color parameters, $L^{*}, a^{*}$ and $b^{*}$ of prepared films were measured and presented in Table 1 . The difference of color $\Delta E$ and the saturation (chroma) in color were calculated using the values of control films $\left(\mathrm{TiO}_{2}\right.$ free films) taken as reference. The results showed that $\mathrm{L}^{*}$ values of incorporated films increased with the $\mathrm{TiO}_{2}$ ratio. The L* values significantly rose from 88.30 to $92.22 \pm 0.19$ that can be explained by the white color and light reflective properties of $\mathrm{TiO}_{2}$. The increased $\mathrm{L}^{*}$ value demonstrated that films became brighter with the addition of $\mathrm{TiO}_{2}$, which is in accordance with the visual observations. In addition, the incorporation of $\mathrm{TiO}_{2}$ increased the $\mathrm{b}^{*}$ values, which indicating the leaning toward yellow color. In contrast, $\mathrm{TiO}_{2}$ incorporation leads to a small decrease in $\Delta \mathrm{E}$ values and a significant decrease ( $p \otimes 0.05)$ in chroma values indicating a reduction in films color saturation. Table 1 also shows no significant difference $(p>0.05)$ in redness $a^{*}$ values between incorporated film samples. Similar results for agar films incorporated by $\mathrm{TiO}_{2}$ particles were described by $\mathrm{Vejdan}$ et al. [13]. Jamróz et al. [17] reported that the percentage of $\mathrm{TiO}_{2}$ particles has to be carefully controlled to keep the initial color of the coated product when films or coating based of chitosan/CMC were applied.

Table 1

Surface color, mecanical, thermal properties and water solubility of the composite films.

\begin{tabular}{|c|c|c|c|c|c|c|c|c|c|c|}
\hline & $\mathrm{L}^{*}$ & $a^{*}$ & $b^{*}$ & $\Delta \mathrm{E}$ & Chroma & $\begin{array}{l}\text { Thickness } \\
(\mu \mathrm{m})\end{array}$ & $\mathrm{T}_{\mathrm{g}} 1\left({ }^{\circ} \mathrm{C}\right)$ & $\mathrm{T}_{\mathrm{g}} 2\left({ }^{\circ} \mathrm{C}\right)$ & TS (MPa) & EAB (\%) \\
\hline Control & $88.30 \pm 0.09^{b}$ & $0.96 \pm 0.09^{b}$ & $0.94 \pm 0.13^{b}$ & $92.37 \pm 0.87^{a}$ & $3.38 \pm 0.16^{a}$ & $\begin{array}{l}61.02 \pm 2.14 \\
\mathrm{a}\end{array}$ & $-59.12 \pm 2.65$ & - & $\begin{array}{l}4.04 \pm 0.23 \\
b\end{array}$ & $\begin{array}{l}200.95 \pm 0 . \\
\mathrm{a}\end{array}$ \\
\hline $\begin{array}{l}\text { F- } \\
\text { GTiO }_{2} \\
0.01 \%\end{array}$ & $89.41 \pm 0.03^{b}$ & $1.07 \pm 0.01^{\mathrm{a}}$ & $1.06 \pm 0.04^{b}$ & $91.89 \pm 0.19^{a}$ & $1.45 \pm 0.05^{b}$ & $\begin{array}{l}60.14 \pm 2.12 \\
\mathrm{a}\end{array}$ & $-60.12 \pm 2.34$ & $-20.54 \pm 0.92$ & $\begin{array}{l}4.67 \pm 0.47 \\
b\end{array}$ & ${ }_{b}^{180.88 \pm 2}$ \\
\hline $\begin{array}{l}\text { F- } \\
\text { GTiO }_{2} \\
0.02 \%\end{array}$ & $91.47 \pm 0.15^{a}$ & $1.04 \pm 0.08^{a}$ & $1.97 \pm 0.08^{a}$ & $91.48 \pm 0.16^{b}$ & $1.52 \pm 0.29^{b}$ & $\begin{array}{l}59.25 \pm 2.36 \\
\text { a }\end{array}$ & $-55.16 \pm 1.25$ & $-15.58 \pm 1.60$ & $\begin{array}{l}5.31 \pm 0.54 \\
\text { a }\end{array}$ & $\begin{array}{l}175.12 \pm 0 . \\
c\end{array}$ \\
\hline $\begin{array}{l}\text { F- } \\
\mathrm{GTiO}_{2} \\
0.03 \%\end{array}$ & $92.22 \pm 0.19^{a}$ & $1.02 \pm 0.06^{\mathrm{a}}$ & $2.28 \pm 0.03^{a}$ & $90.41 \pm 0.02^{\mathrm{C}}$ & $0.78 \pm 0.17^{c}$ & $\begin{array}{l}59.63 \pm 2.50 \\
a\end{array}$ & $-30.56 \pm 1.89$ & $-15.78 \pm 1.02$ & $\begin{array}{l}5.34 \pm 0.57 \\
a\end{array}$ & $\begin{array}{l}171.90 \pm 1 \\
c\end{array}$ \\
\hline
\end{tabular}

Tg: glass transition temperature; TS: tensile strength; EAB: elongation at break; WS: water solubility. F-GTiO $20.01,0.02$ and $0.03 \%$ indicate Gelatin-based Film at levels of $0.01,0.02$ and $0.03 \%$, respectively. All measurements were performed at $25^{\circ} \mathrm{C}$ and $\mathrm{RH}=50 \%$. ${ }^{\text {ab,c,d }}$ Different letters in the same column indicate si differences $(p<0.05)$.

The objective of the determination of UV-visible spectroscopy of films is not only to examine barrier properties of films against light but also to investigate changes observed in visible appearance, which was affected by adding different $\mathrm{TiO}_{2}$ ratios. The absorption spectra were measured spectrophotometrically in 
the range of $200-800 \mathrm{~nm}$ and the spectra values were presented in Table2. All films revealed a high transmittance values (75.19-80.37\%) in the visible range $(400-800 \mathrm{~nm})$. However, the incorporation of $\mathrm{TiO}_{2}$ generated a significant decrease $(p \otimes 0.05)$ in the transmittance values of the different films. The metallic nature with the crystalline structure of $\mathrm{TiO}_{2}$ may cause this drop in transmittance values due to light diffraction and reflection. Indeed, the large specific surface area and high refractive index of $\mathrm{TiO}_{2}$ particles can greatly facilitate the diffuse reflection of light on their interface [18].

Table 2

Transmittance (\%) and opacity (\%) of the composite films.

\begin{tabular}{|c|c|c|c|c|c|c|c|c|c|}
\hline \multirow[b]{2}{*}{$\begin{array}{l}\text { Wave } \\
\text { numbers } \\
(\mathrm{nm})\end{array}$} & \multicolumn{8}{|c|}{ Transmittance } & \multirow[t]{2}{*}{ Opacity } \\
\hline & 200 & 250 & 300 & 400 & 500 & 600 & 700 & 800 & \\
\hline Control & $0.11 \pm 0.02^{\mathrm{a}}$ & $25.7 \pm 1.50^{\mathrm{a}}$ & $62.19 \pm 1.50^{\mathrm{a}}$ & $75.19 \pm 1.64^{a}$ & $78.68 \pm 1.23^{a}$ & $80.37 \pm 2.22^{\mathrm{a}}$ & $80.00 \pm 1.89^{a}$ & $79.57 \pm 1.99^{a}$ & $1.51 \pm 0.08^{d}$ \\
\hline $\begin{array}{l}\text { F-GTiO } \\
0.01 \%\end{array}$ & $0.08 \pm 0.01^{b}$ & $15.00 \pm 0.50^{b}$ & $30.96 \pm 1.20^{b}$ & $31.30 \pm 1.05^{\mathrm{b}}$ & $32.48 \pm 1.45^{b}$ & $36.69 \pm 1.32^{b}$ & $41.02 \pm 1.64^{b}$ & $45.69 \pm 0.50^{b}$ & $7.39 \pm 0.79^{c}$ \\
\hline $\begin{array}{l}\text { F-GTiO } \\
0.02 \%\end{array}$ & $0.05 \pm 0.01^{b}$ & $5.72 \pm 0.90^{c}$ & $13.19 \pm 0.56^{c}$ & $12.20 \pm 0.89^{c}$ & $13.22 \pm 1.05^{\mathrm{c}}$ & $16.97 \pm 1.54^{c}$ & $21.74 \pm 1.70^{c}$ & $27.02 \pm 1.23^{c}$ & $13.48 \pm 1.09^{b}$ \\
\hline $\begin{array}{l}\mathrm{F}-\mathrm{GTiO}_{2} \\
0.03 \%\end{array}$ & $0.08 \pm 0.01^{b}$ & $1.91 \pm 0.70^{d}$ & $3.15 \pm 0.56^{d}$ & $1.98 \pm 0.20^{d}$ & $2.30 \pm 0.45^{d}$ & $3.75 \pm 0.89^{d}$ & $6.19 \pm 0.69^{d}$ & $9.55 \pm 0.58^{d}$ & $\begin{array}{l}30.45 \pm 0.87 \\
\mathrm{a}\end{array}$ \\
\hline
\end{tabular}

As compared to the visible range, the UV light transmission in the range of 200-300 nm of control films was already quite low (Table 2). This could be caused by the presence of high content of aromatic amino acids in fish gelatin especially tyrosine and phenylalanine that are sensitive chromophores absorbing light below $300 \mathrm{~nm}$. Moreover, UV transmission of films also decreased with the $\mathrm{TiO}_{2}$ ratio increase. $\mathrm{TiO}_{2}$ particles can cause photo-catalysis by absorbing more ultraviolet light [13]. The same results were described by Vejdan al. [13], who incorporated $\mathrm{TiO}_{2}$ in gelatin-agar films.

Opacity that reflected the measurement of films transparency was evaluated by the determination of how much light passes through it [13]. Table 2 presented the opacity values of the incorporated films with different ratios of $\mathrm{TiO}_{2}$ particles. The opacity values of all films increased as the amount of $\mathrm{TiO}_{2}$ increased confirming the previous observation and explanations. The same results were reported by Vejdan et al. [13] and Kochkina et al. [19]. The obtained results could be explained by the whitening characteristic of $\mathrm{TiO}_{2}$ particles and light reflectance. In addition, film thickness was also an important factor, which could affect strongly opacity values of films, but in our case, it is considered as constant (Table 1).

\subsection{FTIR-ATR analysis}

In order to explain chemical changes in gelatin films structure after incorporation of different ratios of $\mathrm{TiO}_{2}$ particles, FTIR spectra were investigated. The $\mathrm{FTIR}$ spectra of all prepared gelatin films in the spectral range between 600 and $4000 \mathrm{~cm}^{-1}$ were shown in Fig. 1. All spectra revealed the absorption of characteristic amides of gelatin. All the films showed similar spectra in the range of $600-1800 \mathrm{~cm}^{-1}$, as observed by Arfat et al. [20]. The most pronounced absorptions appeared at wavenumbers ranging between 1620-1690 $\mathrm{cm}^{-1}$ (amide I, C=O stretching at $\sim 1658.7 \mathrm{~cm}^{-1}$ ), $1540-1600 \mathrm{~cm}-1$ (amide II, N-H groups coupled with C-N stretching at $\sim 1561 \mathrm{~cm}^{-1}$ ) and 1230-1280 cm-1 (amide III C-N and N-H stretch and vibrations of $\mathrm{CH}_{2} \mathrm{groups}^{-1}$ glycine at $\sim 1245 \mathrm{~cm}-1$ ), which were attributed to typical absorptions normally detected for gelatin-based films [21]. Peak detected at $1047 \mathrm{~cm}^{-1}$ was related to the $\mathrm{OH}$ group of glycerol used as a plasticizer. Besides, the addition of $\mathrm{TiO}_{2}$ did not cause significant difference $(p>0.05)$ in FTIR spectra in the term of bands location. However, there

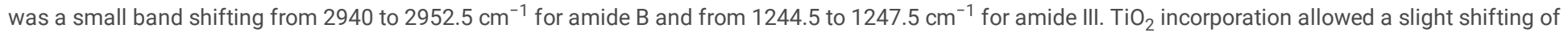
amide $\mathrm{A}$ band from $3325 \mathrm{~cm}^{-1}$ for $\mathrm{F}-\mathrm{GTiO}_{2} 0.01 \%$ to $3337.5 \mathrm{~cm}^{-1}$ for $\mathrm{F}-\mathrm{GTiO}_{2} 0.03 \%$. FTIR spectra of shark gelatin films incorporated with TiO 2 particles showed the same result of amide I, amide II and amide III peaks at wavenumbers of 1637, 1540 and 1240 respectively. In fact, the lower wavenumber of amide $\mathrm{A}$ and broadening of the $\mathrm{OH}$ and $\mathrm{NH}$ vibration bands denoted the converting of the functional groups of protein and the increasing of hydrogen bonding between polymer molecules and particles in the films. According to Alsharaeh et al. [22], $\mathrm{TiO}_{2}$ addition generates a peak at $920 \mathrm{~cm}^{-1}$, which was related to the coupling vibration into the $\mathrm{TiO}_{2}$ particles.

\subsection{Scanning electron microscope (SEM) analysis}

The SEM micrographs of the surface of pure gelatin film and the $\mathrm{TiO}_{2}$ incorporated films were presented in Fig. 2A. The pure gelatin film had homogeneous and smooth surface without any roughness, air bubbles and cracks, which indicated proper mixing of the compounds, whereas, other films demonstrated a heterogeneous surface and small aggregates in the presence of $\mathrm{TiO}_{2}$ particles. The same findings were reported by Alizadeh-sani et al. [23], who also denoted that bio-composite films containing $\mathrm{TiO}_{2}$ had a granular structure; in addition, at low concentration of $\mathrm{TiO}_{2}$ particles the absence of accumulation could indicate the homogeneity and proper dispersion of inorganic particles at low concentrations in biopolymer matrix. Salarbashi et al. [24] who investigated $\mathrm{TiO}_{2}$ incorporation in sobyan proteins film found that as high as the $\mathrm{TiO}_{2}$ ratio increased more protrusions are observed on the surface of these films. These protrusions could be related to the $\mathrm{TiO}_{2}$ location in the surface of films [25]. Zhou et al. [26] also showed a discontinuous phase and high degree of agglomerates in the microstructure of whey protein film containing high $\mathrm{TiO}_{2}$ percentage.

Page 5/10 


\subsection{Film thickness and mechanical property}

In aim to compare the mechanical properties, it was important to check that all films have almost same thickness, and not influenced by the $\mathrm{TiO}_{2}$ incorporation as stated by Vejdan et al. [13]. It is important to study the mechanical properties of the prepared the gelatin-based films containing different ratios of $\mathrm{TiO}_{2}$ particles. Table 3 represents the variation of mechanical properties (tensile strength -TS and elongation at break-EAB) of the different films.

The obtained results showed that increasing $\mathrm{TiO}_{2}$ ratio resulted in a slight increase of the tensile strength film (Table 1), which could be the result of the interfacial interaction between $\mathrm{TiO}_{2}$ particles and biopolymer matrix. In fact, intermolecular hydrogen and/or covalent bonds with gelatin could be established. Indeed, as showed by the observation obtained by scanning electron microscope, film's matrix were charged by the addition of $\mathrm{TiO}_{2}$ particles, so the increase of TS values could be explained by the stability of $\mathrm{TiO}_{2}$ forms during film elongation. Similar findings were reported by Li et al. [27] for chitosan-starch films. However, a reduction in TS values of composite films was observed when $\mathrm{TiO}_{2}$ was added in the ratio of 0.25 and $0.6 \%$ [18]. Zolfi et al. [25] reported that high levels of $\mathrm{TiO}_{2}$ affected the network microstructure of the gelatin films caused by the non-homogeneous dispersion and the agglomeration of the $\mathrm{TiO}_{2}$ particles. The observed differences between studies could be also result of the gelatin source and its composition, the type and ratio of the added plasticizer as well as the preparation and storage methods.

Table 1 also shows that addition of $\mathrm{TiO}_{2}$ up to $0.01 \%$ significantly reduced ( $p \otimes 0.05$ ) the $\mathrm{EAB}$ values of composite films from 200.95 to $180.88 \%$. The decrease of EAB may be in relation with the heterogeneity of film's matrix, which was confirmed by the observations obtained by scanning electron microscope. Indeed, polymer's matrix heterogeneity could make the bond matrix discontinuous and lead to catastrophic failure of the film tensile strength and elongation. In addition, the obtained results could be explained by the interaction between carboxylic and sulfhydryl groups from the fish gelatin amino acids with $\mathrm{TiO}_{2}$ particles [26].

\subsection{Water solubility}

Solubility is an essential property of edible films as they are used as protective coatings of food. In fact, food applications may require water insolubility to enhance product integrity and water resistance particularly for food containing high content of liquids or high water activity. Thus, film solubility was measured and represented in Table 1. The water solubility of control films was $38.94 \%$ in pure water due to the hydrophilic nature of gelatin. The obtained results showed that addition of $\mathrm{TiO}_{2}$ particles to the film matrix resulted in a significant decrease $(p \otimes 0.05)$ in the film solubility (Table 3 ). In this context, it was reported that incorporation of $\mathrm{TiO}_{2}$ in gelatin-agar or in sesame protein isolate based films resulted in their water solubility decrease, which may be related to the biopolymer nature used in the film formation $[13,28]$. The reduction in water solubility could be attributed to the formation of new hydrogen bonds between gelatin helices and the $\mathrm{TiO}_{2}$ particles that leads to a reduction of interactions between the biopolymer and water molecules.

\subsection{Swelling of composite films}

Swelling behavior of fish gelatin based films in distilled water was presented in Fig. $2 \mathrm{C}$ (2). During the first 30 min of soaking, the water absorption of films increased quickly to achieve between 280 and $350 \%$ for all films. The equilibrium water uptake was reached after 120 min from the beginning of the experience. Generally, no regular effect of swelling ratio was obtained while $\mathrm{TiO}_{2}$ addition. Water gain of the incorporated films was highest than the pure gelatin films. The addition of $\mathrm{TiO}_{2}$ from 0.01 to $0.02 \%$ resulted in the increase of swelling ration. However, at $0.03 \%$ of $\mathrm{TiO}_{2}$ water gain of gelatin films decreased significantly ( $p \otimes 0.05)$. The obtained results was in concordance with finding obtained for contact angle and solubility of films. Indeed, the results described previously showed an increase of contact angle and a decrease of solubility of the incorporated films as the content of $\mathrm{TiO}_{2}$ increased, which explain the decrease of swelling ratio. This might be in relation with the size of $\mathrm{TiO}_{2}$ particles, which increased due to their agglomeration into the gelatin matrix and caused the decrease of the hydrophilic nature of $\mathrm{TiO}_{2}$, thus, the decrease of films swelling [29].

\subsection{Water contact angle}

Among the importing properties of biodegradable films, which gives idea about their barrier properties is the water contact angle. In fact, knowing the degree of hydrophobicity of various films is useful in assessing their water absorption properties and what can determine their use potential [28].

The water contact angle and the volume of water droplet of the gelatin-based film containing $\mathrm{TiO}_{2}$ particles were shown in Fig. $2 \mathrm{~B}$ and $\mathrm{C}(1)$, respectively. The obtained results showed that contact angle was between 90 and $130^{\circ}$ indicating that surfaces of all the tested films were hydrophobic in nature. It is important to mention that contact angle of all films decreased by $7.07^{\circ} / \mathrm{min}$. The water contact angle values of these films were higher than $65^{\circ}$, which indicate their low wettability level confirmed by the decrease of swelling ratio reported previously. Additionally, the results obtained for stability of water droplet volume confirm those obtained for water contact angle. Indeed, volume of water droplet was more stable for films incorporated by $\mathrm{TiO}_{2}$ particles, while it showed a dramatically decrease for control films (Pure gelatin films). This finding was in accordance with the decrease of solubility found as the $\mathrm{TiO}_{2}$ content increased. The $\mathrm{TiO}_{2}$ particles addition resulted in increasing the water contact angle, which could indicate that $\mathrm{TiO}_{2}$ might contribute to increase the gelatinbased films hydrophobicity. This result was in concordance with that obtained for the SEM micrographs, which indicate the roughness of the incorporated film surface covered by $\mathrm{TiO}_{2}$ particles, which leads to the increase of hydrophobicity. Moreover, the decreased in hydrophilicity could be the result of the decrease in free hydrophilic groups implicated in new interactions [28]. The same findings were also reported by Salarbashi et al. [24] who investigated TiO 2 incorporation in soybean polysaccharide films. In addition, Fathi et al. [28] found that by incorporation of $\mathrm{TiO}_{2}$ particles, sesame protein isolate based bionanocomposite films tends to become more and more hydrophobic. The low wettability level of the prepared films was very important for biopolymer packaging films because high wettability level can damage them [24].

\subsection{Differential scanning calorimetric}

Page $6 / 10$ 
Differential scanning calorimetric (DSC) analysis was realized in order to determine the thermal properties of the prepared films. Table 1 shows the values of the glass-transition temperature $(\mathrm{Tg})$ of incorporated films, which were determined from the second step of heating. The results showed clear visible change on the $\mathrm{Cp}$, indicating the presence of glass-transition, which implies that all films are mostly amorphous. Indeed, Cp change is significant indicated by the net melting peak of the crystalline fraction of the film. In addition, DCS analysis showed that incorporated films had two values of glass-transition, which implies that incorporation of $\mathrm{TiO}_{2}$ particles in gelatin matrix was not performed properly. Kochkina et al. [19] reported that no glass transition point was detected, while there was a melting state of biopolymer registered at high temperature region.

The pure gelatin film (control) exhibited a $\mathrm{Tg}$ value of $-59.12^{\circ} \mathrm{C}$, which is much lower than those $\left(48.4-50.91^{\circ} \mathrm{C}\right)$ previously reported [30]. With the increase of $\mathrm{TiO}_{2}$ content, $\mathrm{Tg}$ of the incorporated films increased from -60.12 for $\mathrm{F}-\mathrm{GTiO}_{2} 0.01 \%$ to $-30.56^{\circ} \mathrm{C}$ for $\mathrm{F}-\mathrm{GTiO}_{2} 0.03 \%$. The negative value of glass-transition indicate that films were in a rubbery state at room temperatures, which was in accordance with mechanical properties presenting EAB values much higher than $25-30 \%$ and quite low values of TS.

\section{Conclusion}

In the present study, smooth hound gelatin films were prepared with $\mathrm{TiO}_{2}$ particles using a simple procedure involving particles addition and casting. $\mathrm{TiO}_{2}$ particle was incorporated at three levels of $0.01,0.02$ and $0.03 \%$. By adjusting the $\mathrm{TiO}_{2}$ content, mechanical, thermal and spectral properties as well as solubility and contact angle of the investigated films were affected. In fact, $\mathrm{TiO}_{2}$ addition leads to a slight increase of $\mathrm{Tg}$ values specially for $0.03 \% \mathrm{TiO}_{2}$ concentration. The negative values of $\mathrm{Tg}$ was in accordance with the high EAB values, which confirm the rubbery state of films. Furthermore, film opacity was increased indicating the increase of film darkness. On the other hand, at high ratio of $\mathrm{TiO}_{2}$, rigidity (marked by the decrease of $\mathrm{EAB}$ values) and contact angle of films were increased, which was in accordance with the low solubility and swilling ratio measured for the incorporated films. These results suggested that F-GTiO ${ }_{2}$ could be promising as a water-soluble food packaging.

\section{Declarations}

\section{Acknowledgements}

This work was partly supported by the own funds of the UMR PAM laboratory and by the Regional Council of BourgogneFranche-Comte and the "Fonds Européen de Développement Régional (FEDER)" who invested in lab equipment. This work was funded by the Ministry of Higher Education and Scientific Research, Tunisia (Grant no. 18PJEC06-03).

\section{Novelty Statement}

In this study, the effect of agar addition as well as the ultrasound treatment on physico-chemical properties of films was determined, and the authors declare that no conflict of interest with other works.

\section{Data availability statement}

All data generated or analyzed during this study are included in this published article.

\section{References}

1. Félix, M., Lucio-Villegas, A., Romero, A., Guerrero, A.: Development of rice protein bio-based plastic materials processed by injection molding. Ind Crop Prod. 79, 152-159 (2016).

2. Galiano, F., Briceño, K., Marino, T., Molino, A., Christensen, K.V., Figoli, A.: Advances in biopolymer-based membrane preparation and applications. J Membr Sci. 564, 562-586 (2018).

3. Maccari, F., Galeottif Volpi, N.: Isolation and structural characterization of chondroitin sulfate from bony fishes. Carbohydr Polym. 129, 143-147 (2015).

4. Hamdi, M., Hammami, A., Hajji, S., Jridi, M., Nasri, M., Nasri, R.: Chitin extraction from blue crab (Portunus segnis) and shrimp (Penaeus kerathurus) shells using digestive alkaline proteases from P, segnis viscera. Int J Biol Macromol. 101, 455-463 (2017).

5. Abdelhedi, O., Nasri, R., Souissi, N., Nasri, M., Jridi, M.: Sulfated polysaccharides from common smooth hound: Extraction and assessment of anti-ACE, antioxidant and antibacterial activities.Carbohydr Polym. 152, 605-614 (2016).

6. Arumugam, G.K.S., Sharma, D., Balakrishnan, R.M., Ettiyappan, J.B.P.: Extraction, optimization and characterization of collagen from sole fish skin. Sustain Chem Pharm. 9, 19-26 (2018).

7. Zheng, L., Yu, H., Wei, H., Xing, Q., Zou, Y., Zhou, Y., Peng, J.: Antioxidative peptides of hydrolysate prepared from fish skin gelatin usng ginger protease activate antioxidant response element-mediated gene transcription in IPEC-J2 cells. J Funct Foods. 51, 104-112 (2018).

8. Ali, A.M.M., Kishimura, H., Benjakul, S.: Physicochemical and molecular properties of gelatin from skin of golden carp (Probarbus jullieni) as influenced by acid pretreatment and prior-ultrasonication. Food Hydrocoll. 82, 164-172 (2018).

9. Karayannakidis, P.D., Zotos, A.: Fish processing by-products as a potential source of gelatin: a review. J Aquat Food Prod Technol. 25(1), 65-92 (2016).

10. Kamal, O., Pochat-Bohatier, C., Sanchez-Marcano, J.: Development and stability of gelatin cross-linked membranes for copper (II) ions removal from acid waters. Sep Purif Technol. 183, 153-161 (2017).

11. Tayebi, L., Rasoulianboroujeni, M., Cui, Z., Ye, H.: 3D-printed thick structured gelatin membrane for engineering of heterogeneous tissues. Mater Lett. 217, 39-43 (2018). 
12. Shankar, S., Rhim, J.W.: Preparation of sulfur nanoparticle-incorporated antimicrobial chitosan films. Food Hydrocoll. 82, 116-123 (2018).

13. Vejdan, A., Ojagh, S.M., Adeli, A., Abdollahi, M.: Effect of $\mathrm{TiO}_{2}$ nanoparticles on the physico-mechanical and ultraviolet light barrier properties of fish gelatin/agar bilayer film. LWT-Food Sci Technol. 71, 88-95 (2016).

14. Mangalaraj, D., Nithya Devi, D.: Ag/ $\mathrm{TiO}_{2}$ (Metal/Metal oxide) core shell nanoparticles for biological applications. Recent Trends in Materials Science and Applications. 7, 9-17 (2017).

15. Gennadios, A., Handa, A., Froning, G.W., Weller, C.L., Hanna, M.A.: Physical properties of egg White Dialdehyde starch films. J Agr Food Chem. 46(4), 1297-1302 (1998).

16. Lavorgna, M., Piscitelli, F., Mangiacapra, P., Buonocore, G.G.: Study of the combined effect of both clay and glycerol plasticizer on the properties of chitosan films. Carbohydr Polym. 82(2), 291-298 (2010).

17. Jamróz, E., Kulawik, P., Kopel, P.: The effect of nanofillers on the functional properties of biopolymer-based films: A review. Polymers. 11(4), 675 (2019).

18. Liu, C., Xiong, H., Chen, X., Lin, S., Tu, Y.: Effects of nano- $\mathrm{TiO}_{2}$ on the performance of high-amylose starch based antibacterial films. J Appl Polym Sci. 132, 1-7 (2015).

19. Kochkina, N.E., Butikova, O.A.: Effect of fibrous $\mathrm{TiO}_{2}$ filler on the structural, mechanical, barrier and optical characteristics of biodegradable maize starch/PVA composite films. Int J Biol Macromol. 139, 431-439 (2019).

20. Arfat, Y.A., Benjakul, S., Prodpran, T., Sumpavapol, P., Songtipya, P.: Physico-mechanical characterization and antimicrobial properties of fish protein isolate/fish skin gelatin-zinc oxide (ZnO) nanocomposite films. Food Bioproc Tech. 9(1), 101-112 (2016).

21. Nur Hanani, Z., Beatty, E., Roos, Y., Morris, M., Kerry, J.: Development and characterization of biodegradable composite films based on gelatin derived from beef, pork and fish sources. Foods. 2(1), 1-17 (2013).

22. Alsharaeh, E.H., Bora, T., Soliman, A., Ahmed, F., Bharath, G., Ghoniem, M.G., Dutta, J.: Sol-gel-assisted microwave-derived synthesis of anatase $\mathrm{Ag} / \mathrm{TiO}_{2} / \mathrm{GO}$ nanohybrids toward efficient visible light phenol degradation. Catalysts. 7(12), 133 (2017).

23. Alizadeh-Sani, M., Khezerlou, A., Ehsani, A.: Fabrication and characterization of the bionanocomposite film based on whey protein biopolymer loaded with $\mathrm{TiO}_{2}$ nanoparticles, cellulose nanofibers and rosemary essential oil. Ind Crop Prod. 124, 300-315 (2018).

24. Salarbashi, D., Tafaghodi, M., Bazzaz, B.S.F.: Soluble soybean polysaccharide/TiO ${ }_{2}$ bio-nanocomposite film for food application. Carbohydr Polym. 186, 384-393 (2018).

25. Zolfi, M., Khodaiyan, F., Mousavi, M., Hashemi, M.: Development and characterization of the kefiran-whey protein isolate-TiO 2 nanocomposite films. Int. J. Biol. Macromol. 65, 340-345 (2014).

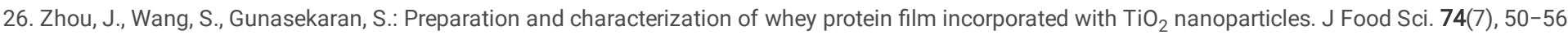
(2009)

27. Li, W., Zheng, K., Chen, H., Feng, S., Wang, W., Qin, C.: Influence of nano titanium dioxide and clove oil on chitosan-starch film characteristics. J. Polym. 11, 1418 (2019).

28. Fathi, N., Almasi, H., Pirouzifard, M.K.: Sesame protein isolate based bio-nanocomposite films incorporated with $\mathrm{TiO}_{2}$ nanoparticles: $\mathrm{Study}_{\mathrm{d}}$ on morphological, physical and photocatalytic properties. Polym Test. 77, 105919 (2019).

29. Hao, Y.Q., Wang, Y.F., Weng, Y.X.: Particle-size-dependent hydrophilicity of $\mathrm{TiO}_{2}$ nanoparticles characterized by Marcus reorganization energy of interfacial charge recombination. J Phys Chem C. 112(24), 8995-9000 (2008).

30. Theerawitayaart, W., Prodpran, T., Benjakul, S., Sookchoo, P.: Properties of films from fish gelatin prepared by molecular modification and direct addition of oxidized linoleic acid. Food Hydrocoll. 88, 291-300 (2019).

\section{Tables}

Table 3 is not available with this version

\section{Figures}




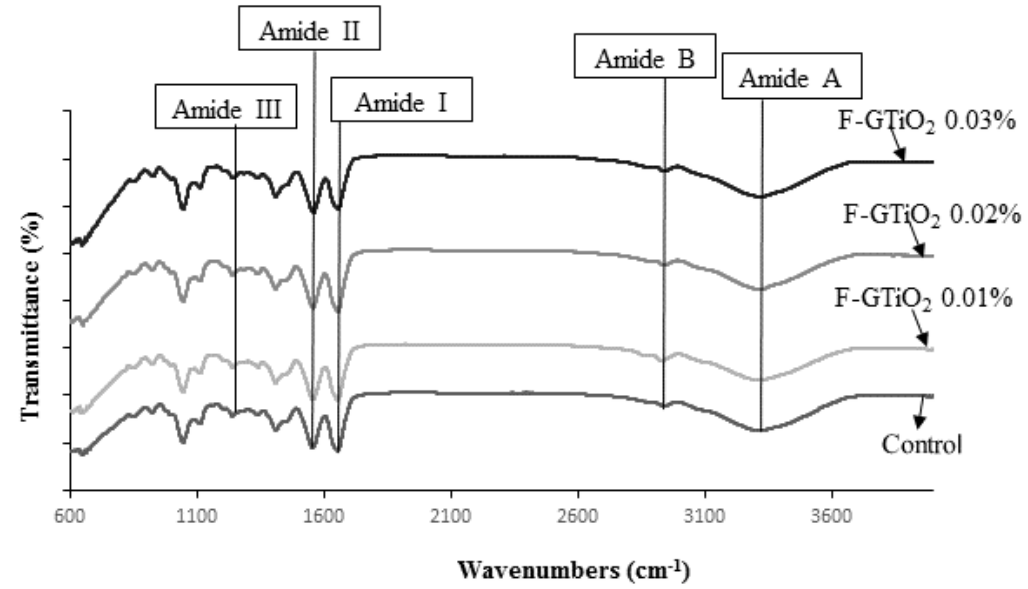

Figure 1

FTIR spectra of gelatin films combined with $\mathrm{TiO}_{2}$ particles at different ratio.
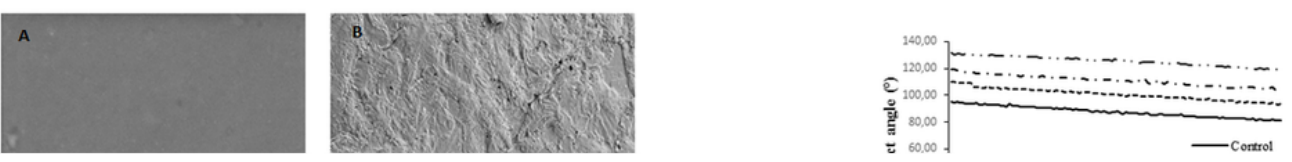

Figure 2

A. SEM micrographs of the surface of pure gelatin film (A: surface, $\mathrm{B}$ : cross section) and the $\mathrm{TiO}_{2}$ incorporated film at $0.03 \%$ (C: surface, $\mathrm{D}$ : cross section).

B. Static water contact angle graphs of different composite films. (A) Water contact angle profile; (B) Pictures of droplet stability.

C. Kinetic of droplet volume deposed on the different blended films (1), and effect of $\mathrm{TiO}_{2}$ content on water sorption profile of different composite films (2). 


\section{Supplementary Files}

This is a list of supplementary files associated with this preprint. Click to download.

- Graphicalabstract.docx 